\title{
Differing Impacts of Black Carbon and Sulfate Aerosols on Global Precipitation and the ITCZ Location via Atmosphere and Ocean Energy Perturbations $\mathscr{O}$
}

\author{
SHUYUN ZHAO \\ Department of Atmospheric Science, School of Environmental Studies, China University of Geosciences, Wuhan, China, and \\ Atmosphere and Ocean Research Institute, The University of Tokyo, Kashiwa, Japan \\ KENTAROH SUZUKI \\ Atmosphere and Ocean Research Institute, The University of Tokyo, Kashiwa, Japan
}

(Manuscript received 19 September 2018, in final form 23 April 2019)

\begin{abstract}
This study explores the effects of black carbon (BC) and sulfate $\left(\mathrm{SO}_{4}\right)$ on global and tropical precipitation with a climate model. Results show that BC causes a decrease in global annual mean precipitation, consisting of a large negative tendency of a fast precipitation response scaling with instantaneous atmospheric absorption and a small positive tendency of a slow precipitation response scaling with the BC-caused global warming. $\mathrm{SO}_{4}$ also causes a decrease in global annual mean precipitation, which is dominated by a slow precipitation response corresponding to the surface cooling caused by $\mathrm{SO}_{4}$. $\mathrm{BC}$ causes a northward shift of the intertropical convergence zone (ITCZ), mainly through a fast precipitation response, whereas $\mathrm{SO}_{4}$ causes a southward shift of the ITCZ through a slow precipitation response. The displacements of the ITCZ caused by $\mathrm{BC}$ and $\mathrm{SO}_{4}$ are found to linearly correlate with the corresponding changes in cross-equatorial heat transport in the atmosphere, with a regression coefficient of about $-3^{\circ} \mathrm{PW}^{-1}$, implying that the ITCZ shifts occur as manifestations of the atmospheric cross-equatorial heat transport changes in response to the $\mathrm{BC}$ and $\mathrm{SO}_{4}$ forcings. The atmospheric cross-equatorial heat transport anomaly caused by BC is basically driven by the $\mathrm{BC}$-induced interhemispheric contrast in instantaneous atmospheric absorption, whereas the atmospheric cross-equatorial heat transport anomaly caused by $\mathrm{SO}_{4}$ is mostly attributable to the response of evaporation. It is found that a slab-ocean model exaggerates the cross-equatorial heat transport response in the atmosphere and the ITCZ shift both for $\mathrm{BC}_{\text {and }} \mathrm{SO}_{4}$, as compared with an ocean-coupled model. This underscores the importance of using an ocean-coupled model in modeling studies of the tropical climate response to aerosols.
\end{abstract}

\section{Introduction}

The climatic effects of aerosols are less constrained than those of greenhouse gases because of the complex ways in which aerosols influence the climate system. For example, hygroscopic aerosols can act as cloud condensation nuclei and change the properties of clouds before changing surface temperature; absorbing aerosols can also change the properties of clouds, but mainly through heating the

Supplemental information related to this paper is available at the Journals Online website: https://doi.org/10.1175/JCLI-D-180616.s1.

Corresponding author: Shuyun Zhao, zhaosy@cug.edu.cn atmosphere (Ming et al. 2010). These make the apparent hydrological sensitivities (the ratio between global-mean precipitation change and surface temperature change) of aerosols more diverse among different climate models than those of greenhouse gases (Samset et al. 2016).

Among the various types of aerosols, black carbon (BC) and sulfate $\left(\mathrm{SO}_{4}\right)$ have been compared more often, because of their distinctively different optical properties (e.g., Kim et al. 2014; Ocko et al. 2014; Lin et al. 2016; Samset et al. 2016; Suzuki and Takemura 2019). Although still with uncertainties in magnitude, it is commonly recognized that $\mathrm{BC}$ has a warming effect and $\mathrm{SO}_{4}$ has a cooling effect on global-mean surface temperature (Boucher et al. 2013; Takemura and Suzuki 2019). The peculiarity of $\mathrm{BC}$ is that it has a negative hydrological 
sensitivity, resulting from a positive global-mean surface temperature response and a negative global-mean precipitation response (e.g., Yoshimori and Broccoli 2008; Ming et al. 2010; Ocko et al. 2014; Samset et al. 2016). Ming et al. (2010) demonstrated that the effect of BC on global-mean precipitation can be divided into a suppressing effect through strong shortwave atmospheric absorption and an enhancing effect through surface warming. This is analogous to the division between fast and slow precipitation responses in Bala et al. (2010). The negative hydrological sensitivity of $\mathrm{BC}$ results from the suppressing effect of atmospheric absorption (or the fast precipitation response), which outweighs the enhancing effect of surface warming (or the slow precipitation response). The fast precipitation response and the associated rapid adjustment processes are receiving increased attention in the science community, as they are very important in understanding the diversity of the precipitation responses to different climate drivers and in different models (Myhre et al. 2017; Stjern et al. 2017). In contrast to $\mathrm{BC}, \mathrm{SO}_{4}$ has a positive hydrological sensitivity, more similar to greenhouse gases, as $\mathrm{SO}_{4}$ has little shortwave absorption in the atmosphere (Ocko et al. 2014; Samset et al. 2016). But the ways in which $\mathrm{SO}_{4}$ and greenhouse gases influence the climate are different.

In climatology, Earth's energy budget features a northward cross-equatorial heat transport in the ocean and a southward cross-equatorial heat transport in the atmosphere (e.g., Marshall et al. 2014; Kang et al. 2015; Stephens et al. 2016). The southward atmospheric cross-equatorial heat transport is associated with a northward crossequatorial moisture transport, as manifested in the upper and lower branches of the Hadley cell. Some studies demonstrated that the northward oceanic cross-equatorial heat transport determines the north-of-the-equator annual mean location of the intertropical convergence zone (ITCZ) (e.g., Frierson et al. 2013; Marshall et al. 2014). Accordingly, perturbations of the hemispheric energy balance can change the latitudinal location of the ITCZ and move it toward the relatively warmed hemisphere (e.g., Chiang and Bitz 2005; Broccoli et al. 2006; Kang et al. 2008, 2009; Hwang et al. 2013; Mahajan et al. 2013; Schneider et al. 2014; Voigt et al. 2014). Therefore, considering the energetic effects of aerosols that are abundant in the Northern Hemisphere (NH), some studies have explored the effects of aerosols, including $\mathrm{BC}$ and $\mathrm{SO}_{4}$, on ITCZ displacement (e.g., Chung and Seinfeld 2005; Hwang et al. 2013; Ocko et al. 2014). Kim et al. (2015) examined the sensitivity of the ITCZ response to the altitude of BC concentration using an aquaplanet GCM. Some studies have demonstrated that anthropogenic aerosols were the dominant drivers of the southward shift of the ITCZ during the second half of the twentieth century; with the mitigation of anthropogenic aerosol emissions in the twenty-first century, the ITCZ is expected to migrate northwardly (Allen et al. 2015; Allen 2015). However, a complete picture of interhemispheric energy budget perturbations, both at the top of the atmosphere (TOA) and the surface, due to $\mathrm{BC}$ and $\mathrm{SO}_{4}$ aerosols, has been missing in previous studies. This has also hindered achieving a clear understanding of how initial perturbations of the interhemispheric energy budget due to instantaneous radiative forcing (RF) are linked to eventual climate responses.

In this study, we explore the following aspects of the climatic effects of $\mathrm{BC}$ and $\mathrm{SO}_{4}: 1$ ) comparing the ways in which the climate responds to the instantaneous RFs of $\mathrm{BC}$ and $\left.\mathrm{SO}_{4} ; 2\right)$ investigating the precipitation responses caused by $\mathrm{BC}$ and $\mathrm{SO}_{4}$ in the context of energy balance constraint at both global and hemispheric scales; 3) quantitatively assessing the relationship between the ITCZ displacements caused by $\mathrm{BC}$ and $\mathrm{SO}_{4}$ and the corresponding atmospheric cross-equatorial heat transport changes; and 4) analyzing the different contributions to the crossequatorial heat transport changes caused by $\mathrm{BC}$ and $\mathrm{SO}_{4}$ and extracting pictures of how $\mathrm{BC}$ and $\mathrm{SO}_{4}$ affect the latitudinal position of the ITCZ. Some of the first two aspects have been discussed by previous studies (e.g., a series of papers from the Precipitation Driver Response Model Intercomparison Project; https:/www.cicero.oslo.no/en/ PDRMIP/PDRMIP-publications). However, we still include them into our discussions in order to again analyze the links between the instantaneous RFs and the climate responses, which have been missing in previous studies, by quantifying relative contributions of different energy components through rapid adjustment, and the slow response to the RFs of $\mathrm{BC}$ and $\mathrm{SO}_{4}$. The quantitative relationship between the atmospheric absorption response and column water vapor response to $\mathrm{BC}$ and $\mathrm{SO}_{4}$ is also investigated in this study, as it largely determines the simulated hydrological sensitivity of aerosols.

Recent studies have highlighted the importance of using a fully coupled ocean model when studying the shift of the ITCZ (e.g., Ocko et al. 2014; Hawcroft et al. 2017; Kay et al. 2016; Green and Marshall 2017). For example, Green and Marshall (2017) found that for a given interhemispheric heating contrast, the ocean responses in a fully coupled ocean model can damp ITCZ shift owing to a coupling between the atmosphere's Hadley cells and the ocean's subtropical cells by the trade winds and their associated surface stresses. However, few among them directly compared fully coupled ocean and slab-ocean models within a common model framework in the context of the climate impacts of $\mathrm{BC}$ and $\mathrm{SO}_{4}$. Therefore, this study pays particular attention to comparing the ITCZ displacements caused by $\mathrm{BC}$ and $\mathrm{SO}_{4}$ between an atmosphere-ocean fully coupled model and atmosphere-slab-ocean coupled model, to better 
understand the relative roles of the atmosphere and ocean in the aerosol-induced ITCZ shift. Section 2 briefly describes the models used in this study and the experimental setup. Results are presented in section 3, followed by conclusions and a summary in section 4 .

\section{Models and experimental setup}

\section{a. Models}

The Model for Interdisciplinary Research on Climate, version 5.2 (MIROC5.2; Watanabe et al.2010), is used in this work, with the standard resolution of T85 (about $1.4^{\circ} \times 1.4^{\circ}$ ) for the atmospheric model and $1^{\circ} \times 1^{\circ}$ for the ocean model. The Spectral Radiation Transport Model for Aerosol Species (SPRINTARS; Takemura et al. 2005, 2009) was implemented in MIROC5.2. SPRINTARS includes five major aerosol types: BC, organic carbon (OC), $\mathrm{SO}_{4}$, soil dust, and sea salt. The last two types of aerosols and dimethyl sulfide (a precursor of $\mathrm{SO}_{4}$ ) are emitted online, whereas prescribed emission data are used for the other aerosols and/or their precursors. SPRINTARS is coupled with radiation and cloud microphysics, so the direct, indirect, and semidirect effects of aerosols are incorporated. SPRINTARS considers the internal mixing between BC and OC. As described in the following section, we fix the $\mathrm{OC}$ emission instead of prescribing its concentration in the atmosphere. This introduces $\mathrm{OC}$ responses to $\mathrm{BC}$ and $\mathrm{SO}_{4}$ emission changes. The emission level of $\mathrm{OC}$ in the preindustrial era was already much higher than that of BC, even in 2000. Therefore, the climate effects of $\mathrm{BC}$ may be influenced by the OC response, especially when the emissions of $\mathrm{BC}$ are assumed insufficiently large. However, fixing aerosol emissions instead of their concentrations also has an advantage, because aerosol emissions are directly controlled by human activities.

A brief introduction to the treatment of $\mathrm{BC}$ and $\mathrm{OC}$ in SPRINTARS is provided here, but a more detailed description is documented in Takemura et al. (2005). The physical processes of $\mathrm{BC}$ and $\mathrm{OC}$, including their emissions, in-cloud activation, subcloud scavenging, in-cloud scavenging, re-emission from droplet evaporation, dry deposition, and gravitational settling, are treated in the same subroutine. Half of the $\mathrm{BC}$ emitted from fossil fuels and aircraft and all of it emitted from biomass burning, domestic activities, and agriculture are assigned the same in-cloud coefficient as OC, and are treated simultaneously with $\mathrm{OC}$ during the processes of wet and dry deposition. These parts of BC are internally mixed with OC. The optical properties of $\mathrm{BC}$ and $\mathrm{OC}$ internally mixing aerosols are divided into three categories according to $\mathrm{BC} / \mathrm{OC}$ concentration ratio, and the corresponding internally mixing aerosol concentrations are calculated as follows:

$$
\begin{aligned}
& \operatorname{QCIM}(1)=\mathrm{QC}, \quad f \geq 0.3, \\
& \begin{array}{c}
\operatorname{QCIM}(1)=\frac{f-0.15}{0.15} \mathrm{QC} \\
\operatorname{QCIM}(2)=\left(1-\frac{f-0.15}{0.15}\right) \mathrm{QC}
\end{array} \\
& \left\{\begin{array}{c}
\operatorname{QCIM}(2)=\frac{f}{0.15} \mathrm{QC} \quad 0.15 \leq f<0.3, \\
\operatorname{QCIM}(3)=\left(1-\frac{f}{0.15}\right) \mathrm{QC}
\end{array}\right.
\end{aligned}
$$

where $f$ is the ratio between $\mathrm{BC}$ and $\mathrm{OC}$ concentrations, $\mathrm{QC}$ represents the total concentration of $\mathrm{BC}$ and $\mathrm{OC}$, and QCIM represents the mixed aerosol concentration, dependent on the $\mathrm{BC} / \mathrm{OC}$ ratio. The remaining half of the $\mathrm{BC}$ emitted from fossil fuels and aircraft is treated as externally mixed with OC.

\section{b. Experimental setup}

In this work, we concentrate on the difference between the $\mathrm{BC}$ - and $\mathrm{SO}_{4}$-induced global and tropical precipitation responses. The prescribed aerosol emission data between 1850 and 2000 from the Intergovernmental Panel on Climate Change (IPCC) representative concentration pathways (http://www.iiasa.ac.at/web-apps/ tnt/RcpDb) are used.

Three groups of experiments with different model configurations are conducted to investigate the equilibrium climate responses to the $\mathrm{BC}$ - and $\mathrm{SO}_{4}$-induced forcings (Table 1). The first group of experiments uses the atmosphere component model of MIROC5.2 with prescribed sea surface temperature (SST) and sea ice, hereafter referred to as the AGCM simulations. The second and third groups replace the prescribed SST and sea ice boundary conditions with MIROC5.2's ocean component model, COCO (CCSR Ocean Component Model; Hasumi 2015) and a mixed layer slab-ocean model, respectively. The second and third groups of experiments are hereafter referred to as the CGCM and slab-ocean model (SOM) simulations, respectively. The slab-ocean model employs a constant mixed layer depth of $50 \mathrm{~m}$, and uses a prescribed $Q$ flux to represent the ocean heat transport (Yoshimori et al. 2017). The AGCM simulations are run for 15 years, with the last 10 years of results used for analysis. The CGCM simulations are run for 100 years, and the SOM simulations are run for 50 years, since a balance is generally achieved after about 20 years (see Fig. S1 in the online supplemental material). The results of the last 30 years for the 
TABLE 1. Simulation setup.

\begin{tabular}{cll}
\hline $\begin{array}{c}\text { Group name } \\
\text { (running years) }\end{array}$ & Expt & \multicolumn{1}{c}{ Aerosol emissions } \\
\hline AGCM (15) & $\mathrm{A}_{\mathrm{REF}}$ & $\mathrm{OC}_{1850} ; \mathrm{SO}_{1850} ; \mathrm{BC}_{1850}$ \\
& $\mathrm{~A}_{1 \mathrm{BC}}$ & $\mathrm{OC}_{1850} ; \mathrm{SO}_{1850} ; \mathrm{BC}_{2000}$ \\
& $\mathrm{~A}_{5 \mathrm{BC}}$ & $\mathrm{OC}_{1850} ; \mathrm{SO}_{1850} ; \mathrm{BC}_{2000} \times 5$ \\
& $\mathrm{~A}_{10 \mathrm{BC}}$ & $\mathrm{OC}_{1850} ; \mathrm{SO} 4_{1850} ; \mathrm{BC}_{2000} \times 10$ \\
& $\mathrm{~A}_{1 \mathrm{SO} 4}$ & $\mathrm{OC}_{1850} ; \mathrm{BC}_{1850} ; \mathrm{SO}_{2000}$ \\
& $\mathrm{~A}_{5 \mathrm{SO} 4}$ & $\mathrm{OC}_{1850} ; \mathrm{BC}_{1850} ; \mathrm{SO}_{2000} \times 5$ \\
& $\mathrm{~A}_{10 \mathrm{SO} 4}$ & $\mathrm{OC}_{1850} ; \mathrm{BC}_{1850} ; \mathrm{SO}_{2000} \times 10$ \\
& $\mathrm{C}_{\mathrm{REF}}$ & $\mathrm{OC}_{1850} ; \mathrm{SO}_{1850} ; \mathrm{BC}_{1850}$ \\
& $\mathrm{C}_{1 \mathrm{BC}}$ & $\mathrm{OC}_{1850} ; \mathrm{SO}_{1850} ; \mathrm{BC}_{2000}$ \\
& $\mathrm{C}_{5 \mathrm{BC}}$ & $\mathrm{OC}_{1850} ; \mathrm{SO}_{1850} ; \mathrm{BC}_{2000} \times 5$ \\
& $\mathrm{C}_{10 \mathrm{BC}}$ & $\mathrm{OC}_{1850} ; \mathrm{SO}_{1850} ; \mathrm{BC}_{2000} \times 10$ \\
& $\mathrm{C}_{1 \mathrm{SO} 4}$ & $\mathrm{OC}_{1850} ; \mathrm{BC}_{1850} ; \mathrm{SO}_{2000}$ \\
& $\mathrm{C}_{5 \mathrm{SO}}$ & $\mathrm{OC}_{1850} ; \mathrm{BC}_{1850} ; \mathrm{SO}_{2000} \times 5$ \\
& $\mathrm{C}_{10 \mathrm{SO} 4}$ & $\mathrm{OC}_{1850} ; \mathrm{BC}_{1850} ; \mathrm{SO}_{2000} \times 10$ \\
& $\mathrm{~S}_{\mathrm{REF}}$ & $\mathrm{OC}_{1850} ; \mathrm{SO}_{1850} ; \mathrm{BC}_{1850}$ \\
& $\mathrm{~S}_{10 \mathrm{BC}}$ & $\mathrm{OC}_{1850} ; \mathrm{SO}_{1850} ; \mathrm{BC}_{2000} \times 10$ \\
& $\mathrm{~S}_{5 \mathrm{SO} 4}$ & $\mathrm{OC}_{1850} ; \mathrm{BC}_{1850} ; \mathrm{SO}_{2000} \times 5$ \\
\hline
\end{tabular}

CGCM and SOM simulations are used for analysis. It should be noted that to obtain a real equilibrium state requires a longer period than 100 years, to wait for the ocean to fully adjust. But, here, our focus is on comparing $\mathrm{BC}$ and $\mathrm{SO}_{4}$. Thus, a quasi-equilibrium state is used, as we found that besides the TOA net radiation (Fig. S1), the global-mean surface temperature change and the ITCZ shift caused by aerosols do not change very much after 30 years in CGCM simulations (figures not shown).

The simulations are performed with the emissions of $\mathrm{BC}$ and $\mathrm{SO}_{4}$ perturbed globally. For this purpose, three levels of emission magnitudes are assumed for $\mathrm{BC}$ and $\mathrm{SO}_{4}$ in the AGCM and CGCM simulations: 1, 5, and 10 times the 2000 emission magnitudes (denoted as 1BC and $1 \mathrm{SO}_{4}, 5 \mathrm{BC}$ and $5 \mathrm{SO}_{4}$, and $10 \mathrm{BC}$ and $10 \mathrm{SO}_{4}$, respectively). The emissions of $\mathrm{OC}$ are fixed as per those in 1850, and the emissions of soil dust and sea salt aerosols are turned off. The CGCM and SOM simulations are compared with each other to examine the ocean's role in modulating the precipitation responses to $\mathrm{BC}$ and $\mathrm{SO}_{4}$, particularly over the tropical region. For this comparison, only the $10 \mathrm{BC}$ and $5 \mathrm{SO}_{4}$ cases are conducted in the SOM experiment group to analyze the pronounced responses of precipitation. In each group, the experiment with all prescribed aerosol emissions in 1850 is used as reference; except for the emissions of $\mathrm{BC}$ and $\mathrm{SO}_{4}$, all model settings among the different experiments are identical.

\section{c. Analytical method}

By analyzing the results of the first two groups of experiments (i.e., AGCM and CGCM), we can separately quantify the instantaneous radiative forcing (RF), rapid adjustment, and climate response for $\mathrm{BC}$ and $\mathrm{SO}_{4}$, as well as the fast and slow precipitation responses induced by $\mathrm{BC}$ and $\mathrm{SO}_{4}$ following the approach of Samset et al. (2016). In the rest of this section, we provide a brief introduction to how RF, rapid adjustment, and response are calculated in this study. A flowchart is also given as an auxiliary illustration (Fig. 1).

RF means the instantaneous net radiation change at the TOA when introducing a forcing agent, while keeping the states of the atmosphere and the surface unchanged. In this work, RF includes aerosols' direct effect and the Twomey effect (Twomey 1977). The model we use can diagnose the direct effect of aerosols by invoking the radiation module twice at each step in a single AGCM simulation - once with aerosols and then without aerosols. The difference in TOA net radiation between the two radiative calculations is considered as the aerosols' direct effect. The Twomey effect can also be diagnosed, using a method analogous to that for the aerosols' direct effect, except the two invocations of the radiation module are replaced by one with a prescribed cloud droplet radius and the other with a prognostic cloud droplet radius (based on the aerosol number concentration). Finally, RF is calculated as the direct and Twomey effects of aerosols in simulations with aerosol emissions perturbed minus those in the reference simulation.

Rapid adjustment caused by a forcing agent consists of the TOA net radiation changes from the adjustments in the atmosphere and on the land, but the ocean is not allowed to change. For different forcing agents, rapid adjustments can offset or amplify RF to varying degrees (Smith et al. 2018). Before calculating the rapid adjustment caused by aerosols, we first need to calculate the aerosols' effective RF-a concept recommended by the IPCC AR5 (Boucher et al. 2013). In this work, the effective RF caused by aerosols is calculated as the TOA net radiation difference between two AGCM simulationsone using present-day aerosol emissions and the other using preindustrial aerosol emissions. Then, the rapid adjustment caused by aerosols can be obtained by subtracting their RF from the corresponding effective RF. Rapid adjustment can be further divided into a cloud component and a noncloud component. Noncloud rapid adjustment is calculated with the same approach as rapid adjustment, but under clear-sky conditions (if not specified, the radiative calculation is under all-sky condition in this work). Then, cloud rapid adjustment can be calculated as the residual of rapid adjustment and its noncloud component.

The response to aerosols results from the aerosolinduced change in global-mean surface temperature. 


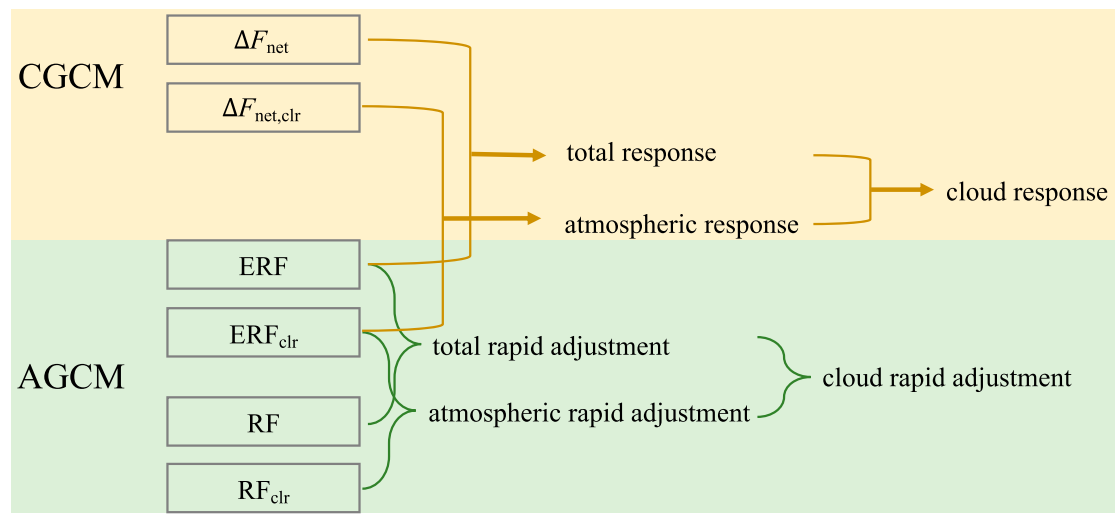

FIG. 1. Flowchart showing how the RF, rapid adjustment, and response are calculated in this study. Note that $\Delta F_{\text {net }}$ and $\Delta F_{\text {net,clr }}$ mean the TOA net radiation changes caused by a forcing agent under all-sky and clear-sky conditions calculated from two CGCM simulations; ERF and $\mathrm{ERF}_{\text {clr }}$ mean the effective RFs caused by a forcing agent under all-sky and clear-sky conditions calculated from two AGCM simulations; and $\mathrm{RF}$ and $\mathrm{RF}_{\text {clr }}$ can be first diagnosed using a double-call method in one AGCM simulation. After that, $\mathrm{RF}$ and $\mathrm{RF}_{\mathrm{clr}}$ are calculated as the difference between perturbed and reference AGCM simulations. The double-call method means one invocation of radiation scheme with and the other one without aerosols when calculating aerosol direct effect, or one with prognostic and the other one with prescribed cloud droplet radius when calculating aerosol Twomey effect. Brackets indicate the difference between two variables.

Before calculating the response to aerosols, we first need to calculate the total TOA net radiation change caused by aerosols using CGCM simulations (Fig. 1), analogous to the method for calculating the aerosols' effective RF. Then, the response to aerosols can be obtained by subtracting the aerosols' effective RF from the corresponding total TOA net radiation change. The response can also be divided into a cloud component and a noncloud component, analogous to rapid adjustment.

\section{Results}

\section{a. RF, rapid adjustment, and response at the TOA}

The three components estimated above (RF, rapid adjustment, and response) correspond to different time scales of the net radiation change at the TOA in response to a given forcing agent. When the climate regains its balance, the sum of the three terms approaches a near-zero global-mean value (though often not exactly zero because of the change in oceanic heat storage), which means rapid adjustment plus response is approximately $-\mathrm{RF}$. Therefore, the relative magnitudes of rapid adjustment and response indicate how the climate system responds to the RF due to a given forcing agent over two different time scales.

The zonal-mean RF, rapid adjustment, and response for $\mathrm{BC}$ and $\mathrm{SO}_{4}$ are shown in Fig. 2. The zonal-mean values (here and hereafter) are weighted by $\cos \varphi$ (where $\varphi$ is latitude) so that the area encircled by each curve and the $x$ axis generally equal the corresponding global mean. Owing to its absorption of shortwave radiation, $\mathrm{BC}$ causes positive RF at the TOA, particularly over the tropics of both hemispheres and the midlatitude $\mathrm{NH}$ (Fig. 2a). In response to the BC-induced RF, rapid adjustment takes the primary role, especially over the equatorial region, and cloud rapid adjustment dominates the total rapid adjustment of BC (Fig. 2c). In global annual mean terms, the normalized magnitudes of cloud and noncloud rapid adjustments relative to $\mathrm{RF}$ for $\mathrm{BC}$ are -0.42 [ -0.51 to -0.33 (minimum to maximum among different aerosol emission levels; the same hereafter)] and $-0.29(-0.33$ to -0.21$)$, respectively. The large negative cloud rapid adjustment for BC is attributable to the increase in low clouds and decreases in middle and high clouds, which exert a cooling effect on TOA radiation. The response to $\mathrm{BC}$ is relatively small, but with large uncertainties, and the cloud and noncloud components of the $\mathrm{BC}$-induced response are opposite in sign over most latitudes (Fig. 2e).

$\mathrm{SO}_{4}$ causes negative $\mathrm{RF}$ at the TOA, especially over the tropical and midlatitude $\mathrm{NH}$ (Fig. 2b). It is found that the rapid adjustment and response for $\mathrm{SO}_{4}$ are generally opposite in sign, and the magnitude of the former is smaller than the latter. In other words, a slow response is the main contributor to the climate response to the $\mathrm{SO}_{4}$-induced $\mathrm{RF}$, especially over the Southern Hemisphere (SH) and $\mathrm{NH}$ high latitudes (Fig. 2b). The global annual mean rapid adjustment for $\mathrm{SO}_{4}$ has a 
(a)

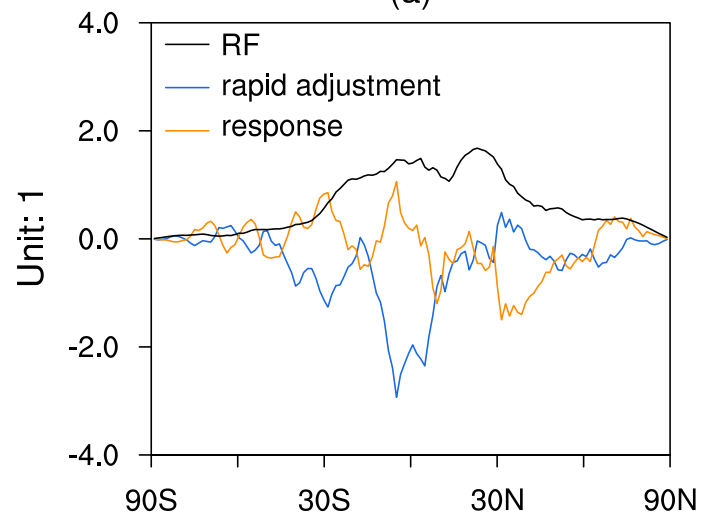

(c)

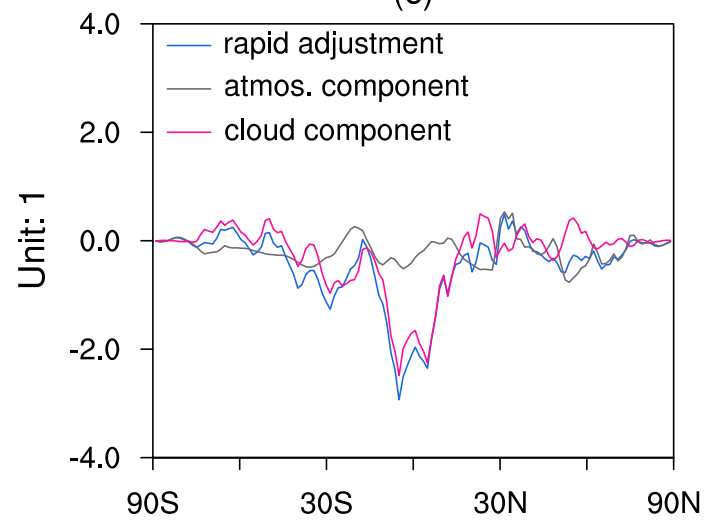

(e)

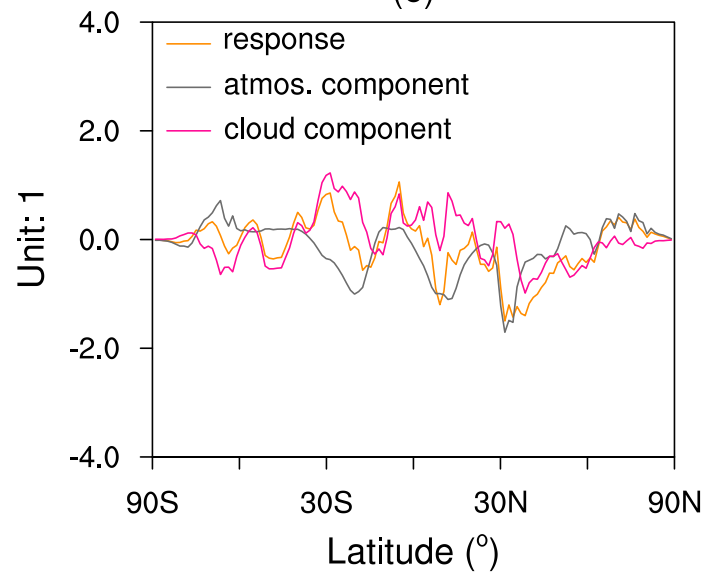

(b)

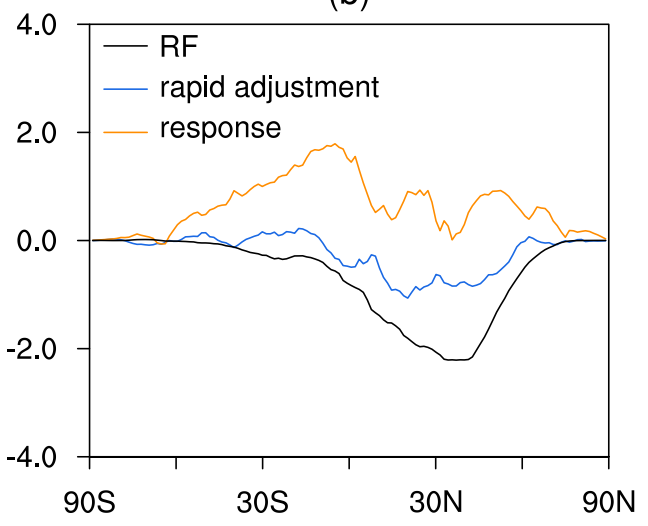

(d)

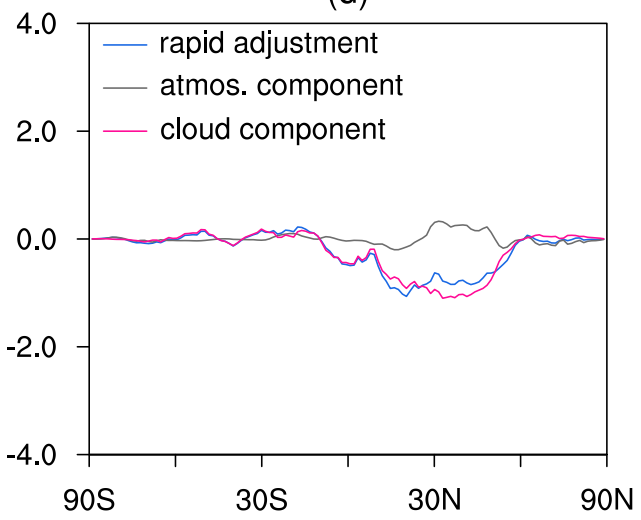

(f)

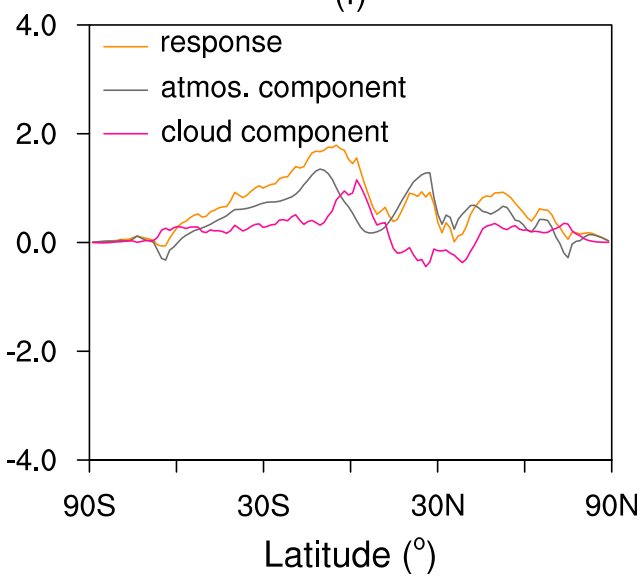

FIG. 2. (top) Zonal-mean (scaled by the cosine of latitude) TOA RF (black lines), rapid adjustment (blue lines), and response (orange lines) caused by (a) $\mathrm{BC}$ and (b) $\mathrm{SO}_{4}$. (middle) The rapid adjustments caused by (c) $\mathrm{BC}$ and (d) $\mathrm{SO}_{4}$ further decomposed into cloud (pink lines) and noncloud (gray lines) components; (bottom) the responses caused by (e) $\mathrm{BC}$ and (f) $\mathrm{SO}_{4}$ also decomposed into cloud (pink lines) and noncloud (gray lines) components. All variables are normalized by the absolute values of the corresponding global-mean RF; thus, their units are all 1 and the results from different experiments (e.g., 1BC, 5BC, and 10BC) can be averaged.

magnitude of 0.35 (0.18 to 0.49 ) relative to $\mathrm{RF}$, which is primarily attributable to the cloud component, especially over the NH low and midlatitudes (Fig. 2d), where middle and low cloud covers increase significantly (not shown). The cloud component of the rapid adjustment caused by $\mathrm{SO}_{4}$ is a manifestation of the $\mathrm{SO}_{4}$ cloud lifetime effect. However, the response to $\mathrm{SO}_{4}$ is largely attributable to the noncloud component over most 
(a)

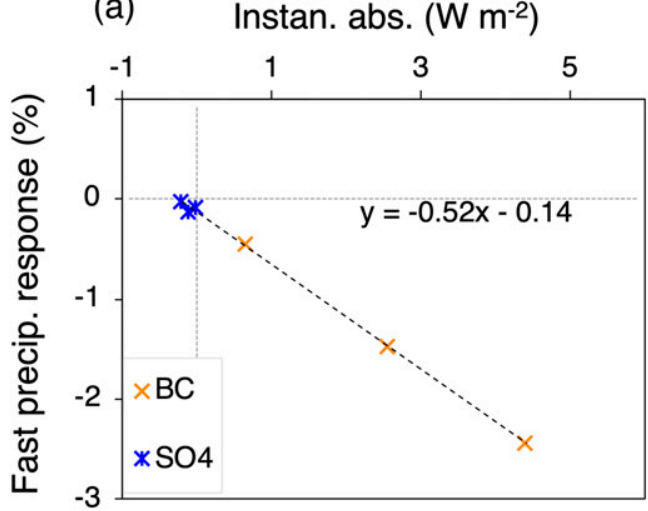

(b)

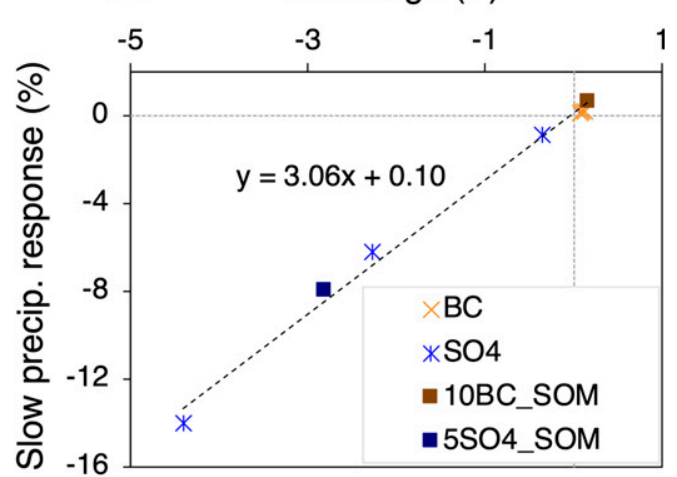

FIG. 3. (a) Fast precipitation response (\%) vs instantaneous atmospheric absorption $\left(\mathrm{W} \mathrm{m}^{-2}\right)$ and (b) slow precipitation response (\%) vs surface temperature change (K).

latitudes (Fig. 2f). The global annual mean cloud and noncloud response have normalized magnitudes relative to the $\mathrm{SO}_{4}$-induced $\mathrm{RF}$ of $-0.30(-0.34$ to -0.28$)$ and $-0.69(-0.87$ to -0.46$)$, respectively. There is a residual (about $0.35 \mathrm{RF}$ ) left for $\mathrm{SO}_{4}$, which is offset by the change in oceanic heat storage. It is also apparent from Fig. $2 \mathrm{f}$ that the cloud response to $\mathrm{SO}_{4}$ is opposite in sign on the two sides of the equator, with a positive sign on the south side and a negative sign on the north side, which amplifies the original interhemispheric energy contrast perturbation induced by $\mathrm{SO}_{4}$, consistent with the ECHAM6-TTT model in Voigt et al. (2014). The contrast in the cloud response to $\mathrm{SO}_{4}$ on the two sides of the equator is consistent with the changes in middle and high clouds, but opposite to the change in low cloud (not shown). The noncloud response to $\mathrm{SO}_{4}$ can change the energy contrast in the vicinity of the equator (Fig. 2f), but overall it does not amplify the original interhemispheric energy contrast perturbation induced by $\mathrm{SO}_{4}$. This is not consistent with Clark et al. (2018) as they found that water vapor feedback can obviously amplify the original interhemispheric energy contrast perturbation induced by altering incoming solar radiation at $\mathrm{NH}$ low and high latitudes. But it should be noted that in Clark et al. (2018), cloud radiative effects were not considered.

The analysis described above suggests that $\mathrm{BC}$ and $\mathrm{SO}_{4}$ interact with the climate in quite different ways. For BC, rapid adjustment is of great importance in the climate response to its RF, leaving a small energy imbalance for the climate to respond; and the rapid adjustment caused by BC can be largely attributed to the adjustment of clouds. These findings imply that the rapid adjustments to $\mathrm{BC}$-induced forcing are sensitive to how $\mathrm{BC}$ and clouds interact with each other. Therefore, estimates of the climate responses to $\mathrm{BC}$ forcing depend heavily on model representations of the hygroscopicity of $\mathrm{BC}$, the internal mixing between $\mathrm{BC}$ and other hygroscopic aerosols, and the performance of cloud schemes. For $\mathrm{SO}_{4}$, however, a slow response takes the primary role in the response to the RF, particularly in the form of the noncloud response largely due to column water vapor change, and the rapid adjustment stemming from the $\mathrm{SO}_{4}$ cloud lifetime effect amplifies the RF.

\section{b. Global-mean precipitation}

Previous studies have demonstrated that the total precipitation response to a given forcing can be decomposed into fast and slow components. We first estimate the fast and total precipitation responses caused by a specific type of aerosol from AGCM and CGCM simulations, respectively; then, the slow precipitation response to the aerosol can be diagnosed by subtracting the fast precipitation response from the corresponding total precipitation response (Samset et al. 2016).

Figure $3 \mathrm{a}$ shows that the fast precipitation responses (both to $\mathrm{BC}$ and $\mathrm{SO}_{4}$ ) have a good linear relationship with the corresponding instantaneous atmospheric absorptions, derived as the RF difference between the TOA and the surface, with a regression coefficient of about $-0.5 \%$ $\left(\mathrm{W} \mathrm{m}^{-2}\right)^{-1}$. This indicates that a certain fraction of the aerosol-induced instantaneous absorption is balanced by the fast response of precipitation (or evaporation). On the other hand, Fig. 3b shows that the slow responses of precipitation to $\mathrm{BC}$ and $\mathrm{SO}_{4}$ are linearly related with the corresponding global-mean surface temperature changes, with a regression coefficient of about $3.0 \% \mathrm{~K}^{-1}$, close to the multimodel ensemble-mean hydrological sensitivity of $\mathrm{SO}_{4}$ reported in Samset et al. (2016) and of many other forcing drivers when the effects of rapid adjustments are removed (Samset et al. 2018).

Figure $3 \mathrm{~b}$ also contains the slow precipitation responses and global-mean surface temperature changes 
caused by $10 \mathrm{BC}$ and $5 \mathrm{SO}_{4}$ obtained from the SOM simulations. It can be seen that the two points from the SOM simulations are generally along the regression line fitted to the CGCM simulations, suggesting that the linear relationship between the slow precipitation response and global-mean surface temperature change is not affected by changing ocean models. However, the absolute values of the slow precipitation responses and global-mean surface temperature changes caused by $10 \mathrm{BC}$ and $5 \mathrm{SO}_{4}$ in the SOM are larger than their counterpart values in the CGCM. It is found that the oceanic heat storage changes are smaller in the SOM than in the CGCM, with a given forcing (see section 3d; Figs. 7c-f). This means that the ocean heat uptake is smaller in the SOM than in the CGCM, and thus the atmospheric response (manifesting as the global-mean surface temperature changes and the slow precipitation responses to $10 \mathrm{BC}$ and $5 \mathrm{SO}_{4}$ here) to a given instantaneous forcing in the SOM tends to be larger than that in the CGCM.

By comparing Figs. 3a and 3b, it is found that the total precipitation response caused by $\mathrm{BC}$ is dominated by its fast component, whereas the total precipitation response caused by $\mathrm{SO}_{4}$ is dominated by its slow component. In global annual mean terms, the total change in the atmospheric radiation budget (the net radiation flux change at the TOA minus that at the surface) is mainly balanced by the total precipitation (or evaporation) response. Therefore, the components of the total atmospheric radiation budget changes caused by $\mathrm{BC}$ and $\mathrm{SO}_{4}$ (see section $3 \mathrm{~d}$; Figs. $7 \mathrm{c}$ and $7 \mathrm{~d}$ ) are the key factors to understanding the differing impacts of these two types of aerosols on precipitation. For BC, instantaneous atmospheric absorption, which is balanced by the fast precipitation response, dominates the total atmospheric radiation budget change. Whereas, for $\mathrm{SO}_{4}$, the instantaneous atmospheric absorption is negligible, and the response in atmospheric absorption (response at the TOA minus that at the surface), which is balanced by the slow precipitation response, dominates the total atmospheric radiation budget change.

According to Suzuki et al. (2017), the response in atmospheric absorption is linearly related with the globalmean surface temperature change, and thus can be regarded as a quantity that connects the slow precipitation response and global-mean surface temperature change. This relationship can be written in a way that is analogous to Eq. (7) in Suzuki et al. (2017), to be tested with our model results, as follows:

$$
-L \Delta P_{\text {slow }} \sim \mathrm{RPS}_{\mathrm{atm}} \sim \mathrm{RPS}_{\mathrm{atm}, \mathrm{clr}} \approx \frac{\alpha \Delta W}{W} \approx \alpha \kappa \Delta T_{s} .
$$

In Eq. (2), $L$ is specific latent heat; $\Delta P_{\text {slow }}$ is the slow precipitation response; $\mathrm{RPS}_{\mathrm{atm}}$ and $\mathrm{RPS}_{\mathrm{atm}, \mathrm{clr}}$ represent the all-sky and clear-sky responses in atmospheric absorption, respectively; $\Delta W / W$ is the response in atmospheric column water vapor; $\Delta T_{s}$ is global-mean surface temperature change; and $\alpha$ and $\kappa$ are empirical parameters that associate $\Delta W / W$ with the response in atmospheric absorption and $\Delta T_{s}$, respectively. Unlike Eq. (7) in Suzuki et al. (2017), a cloud term is not included in Eq. (2), as the contribution from clouds to the response in atmospheric absorption is very small in our model.

Suzuki et al. (2017) found that global precipitation increased with increasing surface temperature at a rate of $\sim 2 \% \mathrm{~K}^{-1}$, based on the twentieth-century historical climate change experiments of Geophysical Fluid Dynamics Laboratory Coupled Model, version 3 (GFDL3). It should be noted that Suzuki et al. (2017) did not separate precipitation change into fast and slow components, and considered both the changes in greenhouse gases and aerosols. Nonetheless, testing Eq. (2) through comparison with Suzuki et al. (2017) can still help us to understand the regression coefficient between the slow precipitation response and global-mean surface temperature change for aerosols $\left(3.0 \% \mathrm{~K}^{-1}\right)$ simulated in this study.

The parameter $\kappa$ is obtained from the regression between aerosol-caused $\Delta W / W$ and $\Delta T_{s}$ (Fig. 4a) and has a value of about $6 \% \mathrm{~K}^{-1}$, consistent with that in Suzuki et al. (2017) and that derived from the Clausius-Clapeyron relationship (Boer 1993; Pall et al. 2007). The term $\alpha \kappa$ can be calculated from the regression between the responses in atmospheric absorption and the global-mean surface temperature changes caused by $\mathrm{BC}$ and $\mathrm{SO}_{4}$ (Fig. 4a) and is about $-2.34 \mathrm{~W} \mathrm{~m}^{-2} \mathrm{~K}^{-1}$, which is more negative than the value of $-1.56 \mathrm{~W} \mathrm{~m}^{-2} \mathrm{~K}^{-1}$ reported in Suzuki et al. (2017). As the parameter $\kappa$ is the same as that in Suzuki et al. (2017), $\alpha$ (about $-0.4 \mathrm{~W} \mathrm{~m}^{-2} \%^{-1}$ ) is more negative than the value of $-0.26 \mathrm{~W} \mathrm{~m}^{-2} \%^{-1}$ reported in Suzuki et al. (2017). The term $\alpha$ is the ratio between the response in atmospheric absorption and the response in atmospheric column water vapor (Stephens and Ellis 2008). To understand why the $\alpha$ simulated here is more negative, we further separate the aerosol-induced response in atmospheric absorption into shortwave and longwave components (Fig. 4b). The regression coefficient between the aerosol-induced shortwave response in atmospheric absorption and the response in atmospheric column water vapor is about $0.15 \mathrm{~W} \mathrm{~m}^{-2} \%^{-1}$, which is the same as that in Suzuki et al. (2017). However, the regression coefficient between the aerosol-induced longwave response in atmospheric absorption and the response in atmospheric column water vapor (about $-0.54 \mathrm{~W} \mathrm{~m}^{-2} \%^{-1}$ ) is more negative than the value of $-0.42 \mathrm{~W} \mathrm{~m}^{-2} \%^{-1}$ reported in Suzuki et al. (2017).

We simulate a larger negative regression coefficient between the longwave atmospheric absorption response 
(a)

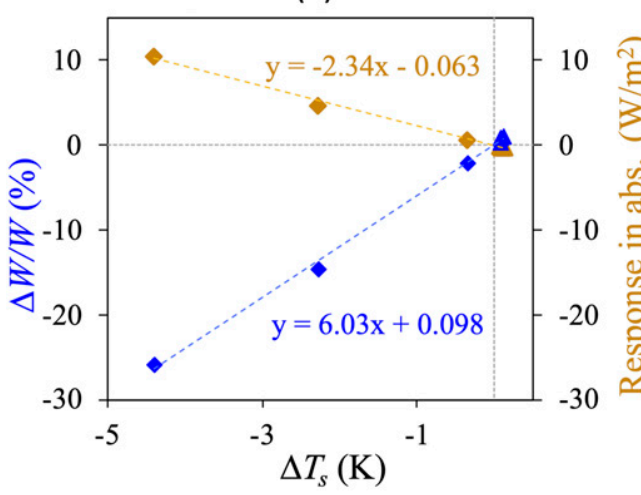

(b)

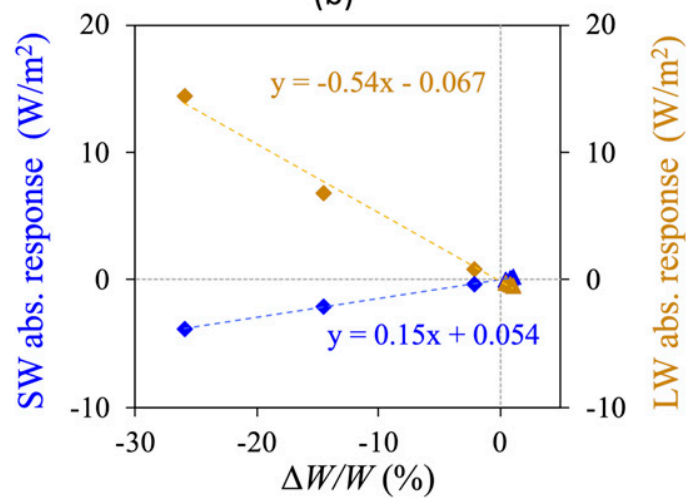

FIG. 4. (a) The responses of atmospheric column water vapor $(\Delta W / W$; blue points; \% $)$ and the responses of atmospheric absorption (brown points; $\mathrm{W} \mathrm{m}^{-2}$ ) vs the global-mean surface temperature changes $\Delta T_{s}(\mathrm{~K})$ caused by aerosols. (b) The shortwave (blue points; $\mathrm{W} \mathrm{m}^{-2}$ ) and longwave (brown points; $\mathrm{W} \mathrm{m}^{-2}$ ) atmospheric absorption responses vs $\Delta W / W(\%)$ caused by aerosols (diamond points for $\mathrm{SO}_{4}$, triangle points for $\mathrm{BC}$ ).

and column water vapor response than that in Suzuki et al. (2017). The reason is that the longwave atmospheric absorption response in Suzuki et al. (2017) includes the absorption of greenhouse gases, which offsets some of the longwave atmospheric cooling caused by increased column water vapor. Besides BC, the hydrological sensitivities of greenhouse gases increase to different degrees when subtracting the fast precipitation response (Samset et al. 2018). For greenhouse gases, subtracting the fast precipitation response means minimizing the offsetting effect of their absorptions on the longwave atmospheric cooling caused by increased column water vapor. For BC, the offsetting effect is from both its longwave and shortwave absorptions, which explains why the hydrological sensitivity of BC shifts from negative to positive when removing the fast precipitation response. The relationship between the atmospheric absorption response and column water vapor response provides a united viewpoint to understanding the connection between the fast precipitation response (scaling with instantaneous absorption) and the slow precipitation response (scaling with surface temperature change) to a specific forcing agent. Besides the optical properties of forcing agents, the atmospheric temperature profile changes induced by different forcing agents (e.g., Hansen et al. 2002; Sherwood and Nishant 2015; Stjern et al. 2017) can also impose some influences on the relationship between the atmospheric absorption response and column water vapor response.

In summary, the total precipitation responses caused by $\mathrm{BC}$ and $\mathrm{SO}_{4}$ are dominated by different components: the fast component for $\mathrm{BC}$ and the slow component for $\mathrm{SO}_{4}$. This is constrained by the different ways in which the two types of aerosols change the atmospheric radiation budget. The linear relationship between the slow precipitation responses and globalmean surface temperature changes caused by $\mathrm{BC}$ and $\mathrm{SO}_{4}$ indeed reflects the constraint of the response in atmospheric absorption, which is mainly associated with atmospheric column water vapor change, on the precipitation response.

\section{c. ITCZ}

Figure 5 shows the zonal-mean fast and slow precipitation responses caused by $\mathrm{BC}$ and $\mathrm{SO}_{4}$. The zonal-mean fast precipitation response caused by $\mathrm{BC}$ indicates a small northward shift of the ITCZ (Fig. 5a), whereas the zonal-mean slow precipitation response caused by $\mathrm{BC}$ shows very little northward shift of the ITCZ (Fig. 5b). It is worth noting that the $1 \mathrm{BC}$ case even causes a southward shift of the ITCZ over the Pacific (not shown). As introduced in section 2, we did not prescribe the OC concentration in our experiments, but fixed its emission level as that in 1850 . The total emission of OC in 1850 is about 3 times that of $\mathrm{BC}$ in 2000. Therefore, for the $1 \mathrm{BC}$ case, the results are easily influenced by the response of the OC concentration in the atmosphere. From Figs. 5c and $5 \mathrm{~d}$, the zonal-mean fast precipitation response caused by $\mathrm{SO}_{4}$ increases slightly near the equator, but with no substantial ITCZ shift, whereas the zonal-mean slow precipitation response caused by $\mathrm{SO}_{4}$ indicates an obvious southward shift of the ITCZ. The ITCZ shifts caused by $\mathrm{BC}$ and $\mathrm{SO}_{4}$ are to some extent consistent with the fast and slow responses of the East Asian summer monsoon to these two types of aerosols in Wang et al. (2017).

The meridional shift of the ITCZ has been shown to bear a close relationship with the change in atmospheric 
(a)

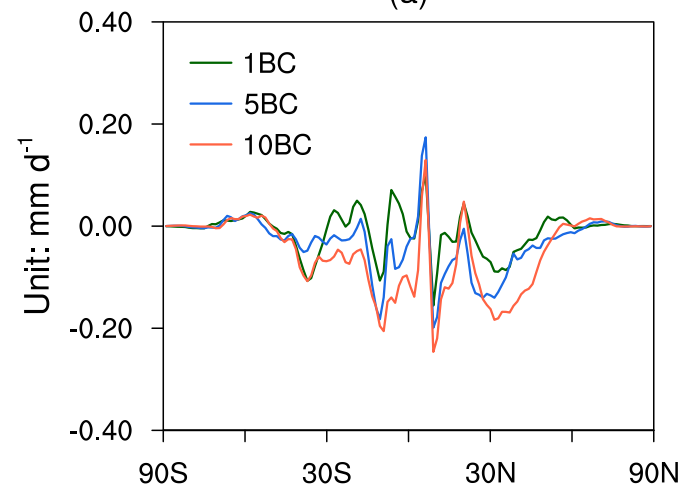

(c)

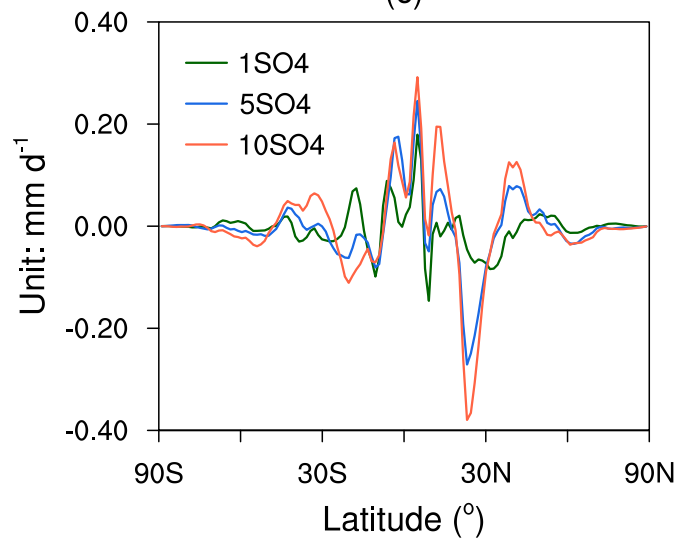

(b)

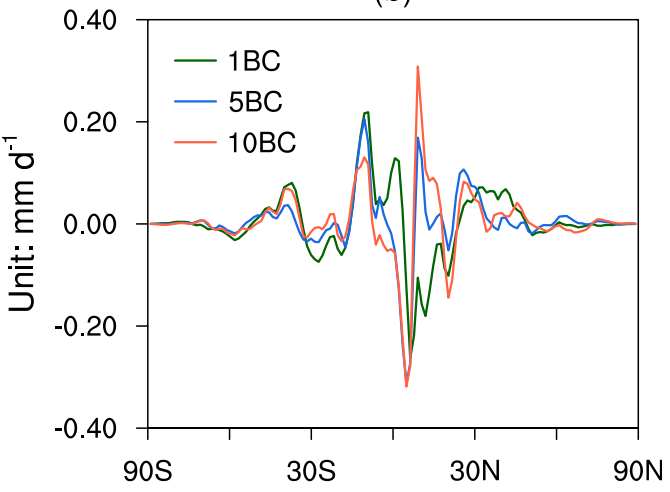

(d)

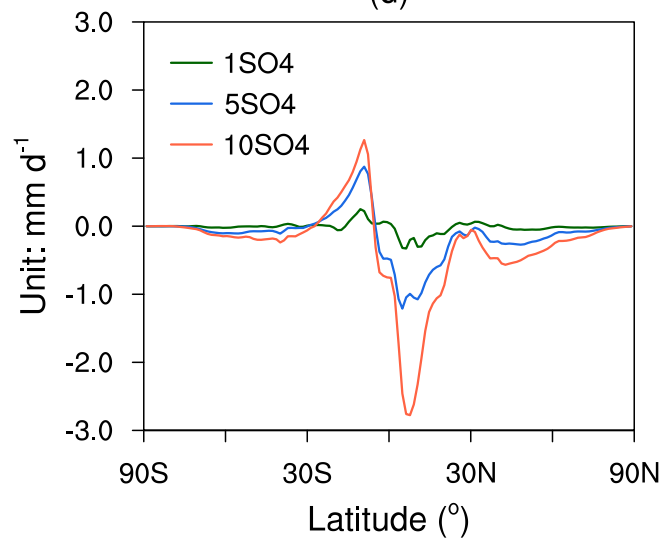

FIG. 5. (left) The zonal-mean fast precipitation responses $\left(\mathrm{mm} \mathrm{day}^{-1}\right)$ caused by (a) $\mathrm{BC}$ and (c) $\mathrm{SO}_{4}$. (right) The zonal-mean slow precipitation responses $\left(\mathrm{mm} \mathrm{day}^{-1}\right)$ caused by (b) $\mathrm{BC}$ and (d) $\mathrm{SO}_{4}$.

cross-equatorial heat transport (e.g., Donohoe et al. 2013; Haywood et al. 2016; Hawcroft et al. 2017; Kay et al. 2016; Voigt et al. 2017). Figure 6a shows a scatterplot of ITCZ displacement versus the change in atmospheric cross-equatorial heat transport. The latitudinal position of the ITCZ is calculated as the precipitation centroid between $15^{\circ} \mathrm{S}$ and $15^{\circ} \mathrm{N}$, and the atmospheric cross-equatorial heat transport is obtained by subtracting the cross-equatorial heat transport in the ocean from the total cross-equatorial heat transport. The computing methods of the total and oceanic meridional heat transport were introduced in many previous studies (e.g., Hawcroft et al. 2017). Figure 6a illustrates that the meridional displacements of the ITCZ caused by $\mathrm{BC}$ and $\mathrm{SO}_{4}$ have a good linear relationship with the corresponding changes in atmospheric cross-equatorial heat transport, with a regression coefficient of about $-3^{\circ} \mathrm{PW}^{-1}$. This is close to the value of $-3.2^{\circ}$ to $-2.4^{\circ} \mathrm{PW}^{-1}$ in Donohoe et al. (2013) and $-4^{\circ} \mathrm{PW}^{-1}$ in Mahajan et al. (2013), but much less negative than the value of $-7.5^{\circ}$ to $-6^{\circ} \mathrm{PW}^{-1}$ reported in Voigt et al. (2017).
The ITCZ displacements caused by $\mathrm{BC}$ and $\mathrm{SO}_{4}$ are compared between the CGCM and SOM using the $10 \mathrm{BC}$ and $5 \mathrm{SO}_{4}$ cases, respectively (Fig. 6b). It is found that the respective northward and southward shifts of the ITCZ caused by $10 \mathrm{BC}$ and $5 \mathrm{SO}_{4}$ are greater in the SOM than in the CGCM. The meridional displacements of the ITCZ versus the changes in atmospheric cross-equatorial heat transport caused by $10 \mathrm{BC}$ and $5 \mathrm{SO}_{4}$ in the SOM are also plotted in Fig. 6a (the two quadrate points). It is found that the meridional displacement of the ITCZ and the change in atmospheric cross-equatorial heat transport caused by $5 \mathrm{SO}_{4}$ in the $\mathrm{SOM}$ are even greater than those by $10 \mathrm{SO}_{4}$ in the CGCM. It is obvious that, in the SOM, the ITCZ displacements and the changes in atmospheric crossequatorial heat transport caused by $10 \mathrm{BC}$ and $5 \mathrm{SO}_{4}$ are more pronounced compared with those in the CGCM. Nevertheless, the ITCZ displacements versus the changes in atmospheric cross-equatorial heat transport simulated in the SOM and CGCM are generally along the same regression line (Fig. 6a), further demonstrating that the ITCZ shifts caused by BC and 
(a)

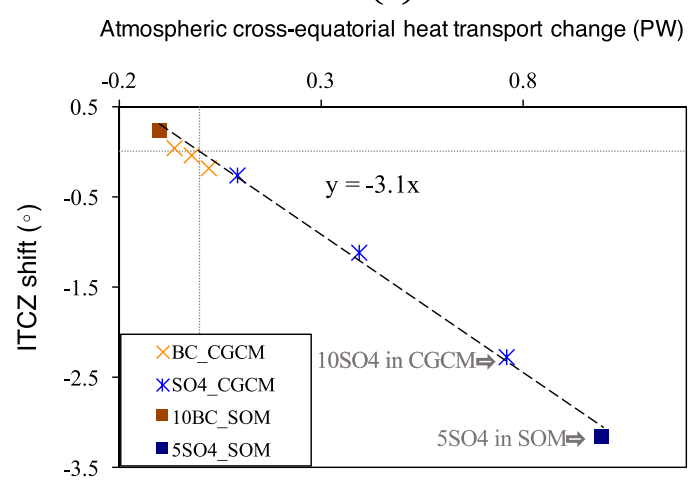

(b)

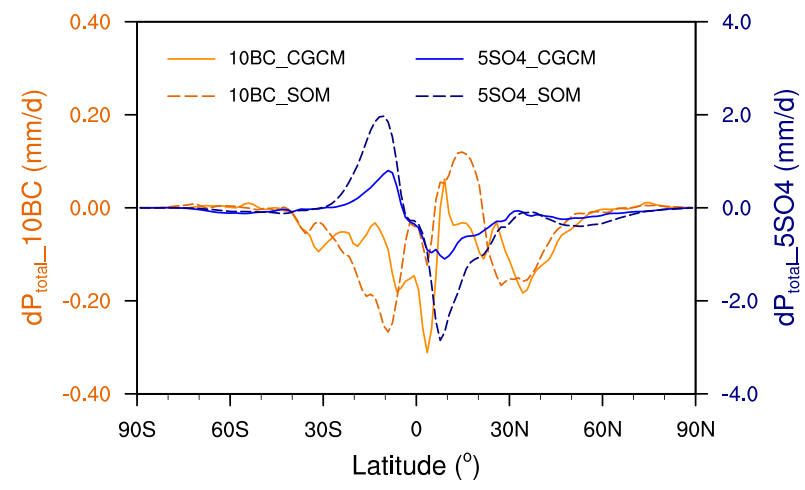

FIG. 6. (a) The ITCZ shifts $\left({ }^{\circ}\right)$ vs the atmospheric crossequatorial heat transport changes (PW) caused by aerosols (orange crosses and blue stars are for $\mathrm{BC}$ and $\mathrm{SO}_{4}$ in the CGCM, respectively; brown and deep blue quadrate points are for $10 \mathrm{BC}$ and $5 \mathrm{SO}_{4}$ in the SOM, respectively). (b) The zonal-mean total precipitation response $\left(\mathrm{mm} \mathrm{day}^{-1}\right)$ caused by $10 \mathrm{BC}\left(\mathrm{dP}_{\text {total }} 10 \mathrm{BC}\right.$, orange lines) and $5 \mathrm{SO}_{4}\left(\mathrm{dP}_{\text {total }} 5 \mathrm{SO} 4\right.$, blue lines $)$ in the $\mathrm{CGCM}$ (solid lines) and SOM (dashed lines).

$\mathrm{SO}_{4}$ are manifestations of the changes in atmospheric cross-equatorial heat transport.

\section{d. Hemispheric energy balance and transport}

To understand the different impacts of $10 \mathrm{BC}\left(5 \mathrm{SO}_{4}\right)$ on atmospheric cross-equatorial heat transport, and thereby on the latitudinal position of the ITCZ under different ocean conditions, the changes in the hemispheric energy balance and cross-equatorial heat transport-both in the atmosphere and the ocean - caused by $10 \mathrm{BC}\left(5 \mathrm{SO}_{4}\right)$ are compared among the AGCM, CGCM, and SOM (Fig. 7). Cross-equatorial heat transport occurs as a response to interhemispheric energy contrast, and in equilibrium the ratio between cross-equatorial heat transport and interhemispheric energy contrast should be around 0.5 . This suggests that all components influencing the interhemispheric contrast of the atmospheric energy budget also contribute to the change in atmospheric cross-equatorial heat transport. The contributions from different components to the atmospheric cross-equatorial heat transport changes are estimated and compared for the $10 \mathrm{BC}$ and $5 \mathrm{SO}_{4}$ cases (Table 2).

In the AGCM, the SST is fixed, and thus the imbalances of energy caused by $10 \mathrm{BC}$ and $5 \mathrm{SO}_{4}$ at the surface do not change the surface temperature. This phenomenon can possibly be interpreted by introducing a hypothetical ocean concept (represented by the dashed boxes in Figs. 7a and 7b). That is, the fixed-SST ocean behaves as if the energy imbalances caused by $10 \mathrm{BC}$ and $5 \mathrm{SO}_{4}$ at the surface are "absorbed" or "counteracted" by the hypothetical ocean rapidly. The interhemispheric energy imbalances caused by $10 \mathrm{BC}$ and $5 \mathrm{SO}_{4}$ are also counteracted by the hypothetical ocean rapidly, as if the hypothetical ocean transports heat in the meridional direction rapidly. For $10 \mathrm{BC}$, the interhemispheric energy imbalance in the atmosphere (more instantaneous atmospheric absorption in the $\mathrm{NH}$ than in the $\mathrm{SH}$ ) occurs to induce the atmospheric cross-equatorial heat transport anomaly besides the quick hypothetical ocean response to the surface interhemispheric energy imbalance. The 10BC case thus causes southward anomalous cross-equatorial heat transports in both the atmosphere and the hypothetical ocean in the AGCM (Fig. 7a). For $5 \mathrm{SO}_{4}$, however, a cross-equatorial heat transport anomaly occurs almost solely in the hypothetical ocean and is negligible in the atmosphere in the AGCM (Fig. 7b), since $\mathrm{SO}_{4}$ has little instantaneous shortwave absorption. This also explains why the fast precipitation response caused by $\mathrm{SO}_{4}$ shows no ITCZ shift (Fig. 5c).

In the CGCM, both $10 \mathrm{BC}$ and $5 \mathrm{SO}_{4}$ result in larger cross-equatorial heat transport anomalies in the atmosphere and smaller cross-equatorial heat transport anomalies in the ocean than they do in the AGCM (Figs. 7c,d). The reason is that, compared with the fixed SST (the quick hypothetical ocean) in the AGCM, the fully coupled ocean in the CGCM reacts more slowly in counteracting the interhemispheric energy imbalances caused by $10 \mathrm{BC}$ and $5 \mathrm{SO}_{4}$ at the surface, sparing time for the atmosphere to respond. For 10BC, the southward atmospheric cross-equatorial heat transport anomaly in the AGCM is basically driven by the interhemispheric contrast in instantaneous atmospheric absorption, the majority of which is offset by the adjustment of evaporation (second column of Table 2). In the CGCM, the response of radiation (evaporation) to $10 \mathrm{BC}$ weakens (enhances) the 10BC-induced southward atmospheric cross-equatorial heat transport anomaly, resulting in a small net increase in the 10BC-induced southward atmospheric cross-equatorial heat transport anomaly, as compared with that in the AGCM (third column of 

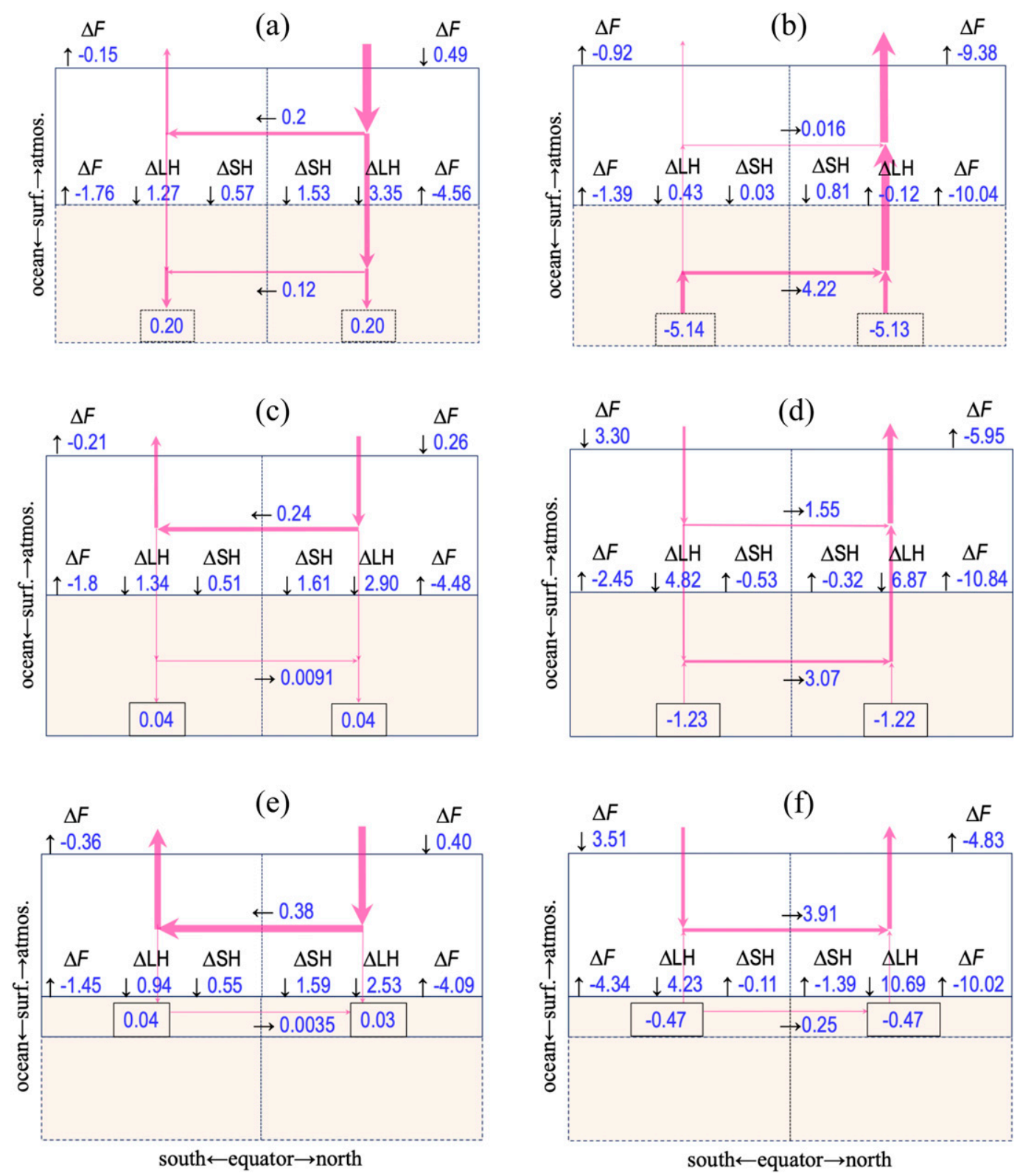

FIG. 7. The changes in hemisphere-mean energy balance and interhemispheric heat transport $\left(\mathrm{W} \mathrm{m}^{-2}\right)$ caused by (a),(c),(e) 10BC and (b),(d),(f) $5 \mathrm{SO}_{4}$ in the (a),(b) AGCM, (c),(d) CGCM, and (e),(f) SOM simulations; $F$, LH, and $\mathrm{SH}$ represent net radiation flux, latent heat, and sensible heat, respectively. Boxed values in the ocean represent the changes in ocean heat storage.

Table 2). For $5 \mathrm{SO}_{4}$, the northward atmospheric crossequatorial heat transport anomaly in the AGCM is very small, and the increase in the northward atmospheric cross-equatorial heat transport anomaly in the CGCM is mainly attributable to the response of evaporation (sixth column of Table 2).

In the SOM, even more cross-equatorial heat transport anomalies caused by $10 \mathrm{BC}$ and $5 \mathrm{SO}_{4}$ are undertaken by the atmosphere than that in the CGCM
(Figs. 7e,f). In the SOM, the $Q$ flux is fixed, which means that the heat transport in the ocean is constant. Therefore, the atmosphere has to take the primary role in responding to the interhemispheric energy imbalances caused by $10 \mathrm{BC}$ and $5 \mathrm{SO}_{4}$. It is found that, for $10 \mathrm{BC}$, the weakening effect of the radiation response to the southward atmospheric cross-equatorial heat transport anomaly in the SOM is smaller than that in the CGCM (fourth column of Table 2), which is the main reason 
TABLE 2. Different contributions $\left(\mathrm{W} \mathrm{m}^{-2}\right)$ to the change in atmospheric cross-equatorial heat transport, where northward is positive. In the columns for the CGCM and SOM, "AGCM + x" means the value in the AGCM plus the contribution from the response. "Abs." is short for instantaneous absorption in the atmosphere; "Adj.atm" and "Adj.cld" represent the noncloud and cloud components of rapid adjustment diagnosed in the atmosphere, respectively.

\begin{tabular}{|c|c|c|c|c|c|c|c|c|}
\hline \multirow[b]{3}{*}{ Radiation } & \multicolumn{4}{|c|}{$10 \mathrm{BC}$} & \multicolumn{4}{|c|}{$5 \mathrm{SO} 4$} \\
\hline & \multicolumn{2}{|c|}{ AGCM } & \multirow{2}{*}{$\frac{\mathrm{CGCM}}{\mathrm{AGCM}+0.15}$} & \multirow{2}{*}{$\frac{\mathrm{SOM}}{\mathrm{AGCM}+0.02}$} & \multicolumn{2}{|c|}{ AGCM } & \multirow{2}{*}{$\frac{\mathrm{CGCM}}{\mathrm{AGCM}+0.53}$} & \multirow{2}{*}{$\frac{\mathrm{SOM}}{\mathrm{AGCM}+1.43}$} \\
\hline & $\begin{array}{l}\text { Abs. } \\
\text { Adj.atm } \\
\text { Adj.cld }\end{array}$ & $\begin{array}{l}-1.98 \\
+0.24 \\
+0.02\end{array}$ & & & $\begin{array}{l}\text { Abs. } \\
\text { Adj.atm } \\
\text { Adj.cld }\end{array}$ & $\begin{array}{l}+0.15 \\
-0.325 \\
+0.08\end{array}$ & & \\
\hline Evaporation & \multicolumn{2}{|c|}{+1.04} & AGCM -0.26 & $\mathrm{AGCM}-0.24$ & \multicolumn{2}{|c|}{-0.275} & $\mathrm{AGCM}+1.3$ & $\mathrm{AGCM}+3.5$ \\
\hline Sensible heat & \multicolumn{2}{|c|}{+0.48} & $\mathrm{AGCM}+0.07$ & $\mathrm{AGCM}+0.04$ & \multicolumn{2}{|c|}{+0.39} & $\mathrm{AGCM}-0.28$ & $\mathrm{AGCM}-1.03$ \\
\hline Total & \multicolumn{2}{|c|}{-0.2} & AGCM - 0.04 & $\mathrm{AGCM}-0.18$ & \multicolumn{2}{|c|}{+0.02} & $\mathrm{AGCM}+1.55$ & $\mathrm{AGCM}+3.9$ \\
\hline
\end{tabular}

why the southward atmospheric cross-equatorial heat transport anomaly caused by $10 \mathrm{BC}$ in the SOM is larger than that in the CGCM. For $5 \mathrm{SO}_{4}$, the larger northward atmospheric cross-equatorial heat transport anomaly in the SOM than that in the CGCM is mostly attributable to the response of evaporation and to a lesser extent to the response of radiation (seventh column of Table 2). It is expected that the anomalies of oceanic crossequatorial heat transport and ocean heat storage caused by $10 \mathrm{BC}$ and $5 \mathrm{SO}_{4}$ in the $\mathrm{SOM}$ should be zero if the running time is long enough and a real equilibrium climate state is achieved, as the $Q$ flux is fixed in SOM simulations. Even though, it is seen that the oceanic cross-equatorial heat transport anomalies caused by $10 \mathrm{BC}$ and $5 \mathrm{SO}_{4}$ are negligible compared with their atmospheric counterparts in the SOM (Figs. 7e,f).

The comparisons above demonstrate that, for a specific forcing agent, the ways in which the climate system responds to the interhemispheric energy imbalance can be very different depending on the oceanic conditions. The change in atmospheric cross-equatorial heat transport caused by aerosols, which determines the ITCZ shift, is underestimated in the AGCM and exaggerated in the SOM, as compared with that in the CGCM. This underscores the importance of employing a fully coupled ocean in modeling studies of tropical precipitation responses.

The different ways in which $\mathrm{BC}$ and $\mathrm{SO}_{4}$ affect the position of the ITCZ are summarized in two schematics (Fig. 8), based on the AGCM and CGCM simulations. To simplify the story, only the largest contributors to the atmospheric cross-equatorial heat transport anomalies caused by $\mathrm{BC}$ and $\mathrm{SO}_{4}$ (Table 2) are given in the schematics. Both $\mathrm{BC}$ and $\mathrm{SO}_{4}$ suppress evaporation more greatly in the $\mathrm{NH}$ than they do in the SH (Figs. 7c,d), which means that the two types of aerosols increase the evaporation in the $\mathrm{SH}$ relative to the $\mathrm{NH}$. For BC, its instantaneous atmospheric absorption in the $\mathrm{NH}$ basically drives the southward atmospheric cross-equatorial heat transport anomaly, which forces a northward crossequatorial moisture transport anomaly (Fig. S2a) and causes the ITCZ to shift northwardly. However, for $\mathrm{SO}_{4}$, the largest contributor to the northward crossequatorial heat transport anomaly is the response of evaporation (i.e., relatively more evaporation in the $\mathrm{SH})$. Consequently, the northward cross-equatorial heat transport anomaly caused by $\mathrm{SO}_{4}$ forces southward cross-equatorial moisture transport (Fig. S2b), even though there is already more evaporation in the SH. In summary, BC causes the ITCZ to shift northward from its more instantaneous atmospheric absorption in the $\mathrm{NH}$, whereas $\mathrm{SO}_{4}$ causes the ITCZ to shift southward, mainly through its excessive suppression of evaporation in the NH. The two processes happen over two different time scales.

\section{Conclusions}

This study explored the differing impacts of $\mathrm{BC}$ and $\mathrm{SO}_{4}$ aerosols on global and tropical precipitation, using the climate model MIROC5.2. BC and $\mathrm{SO}_{4}$ have quite different optical properties, resulting in positive and negative RF at the TOA, respectively. Results show that rapid adjustment, particularly cloud rapid adjustment, plays the primary role in the climate response to the RF of $\mathrm{BC}$. For $\mathrm{SO}_{4}$, in contrast, the noncloud response plays the largest role in the response to the RF at the TOA; the rapid adjustment, which results mainly from the cloud lifetime effect of $\mathrm{SO}_{4}$, amplifies the $\mathrm{SO}_{4} \mathrm{RF}$ by about $35 \%$ in our model.

The total precipitation responses caused by $\mathrm{BC}$ and $\mathrm{SO}_{4}$ are dominated by different components. For BC, the fast precipitation response, which scales with instantaneous atmospheric absorption by approximately $-0.5 \%\left(\mathrm{~W} \mathrm{~m}^{-2}\right)^{-1}$, dominates the total precipitation response. However, for $\mathrm{SO}_{4}$, a slow precipitation response scaling with global-mean surface temperature change according to $\sim 3.0 \% \mathrm{~K}^{-1}$ dominates the total 

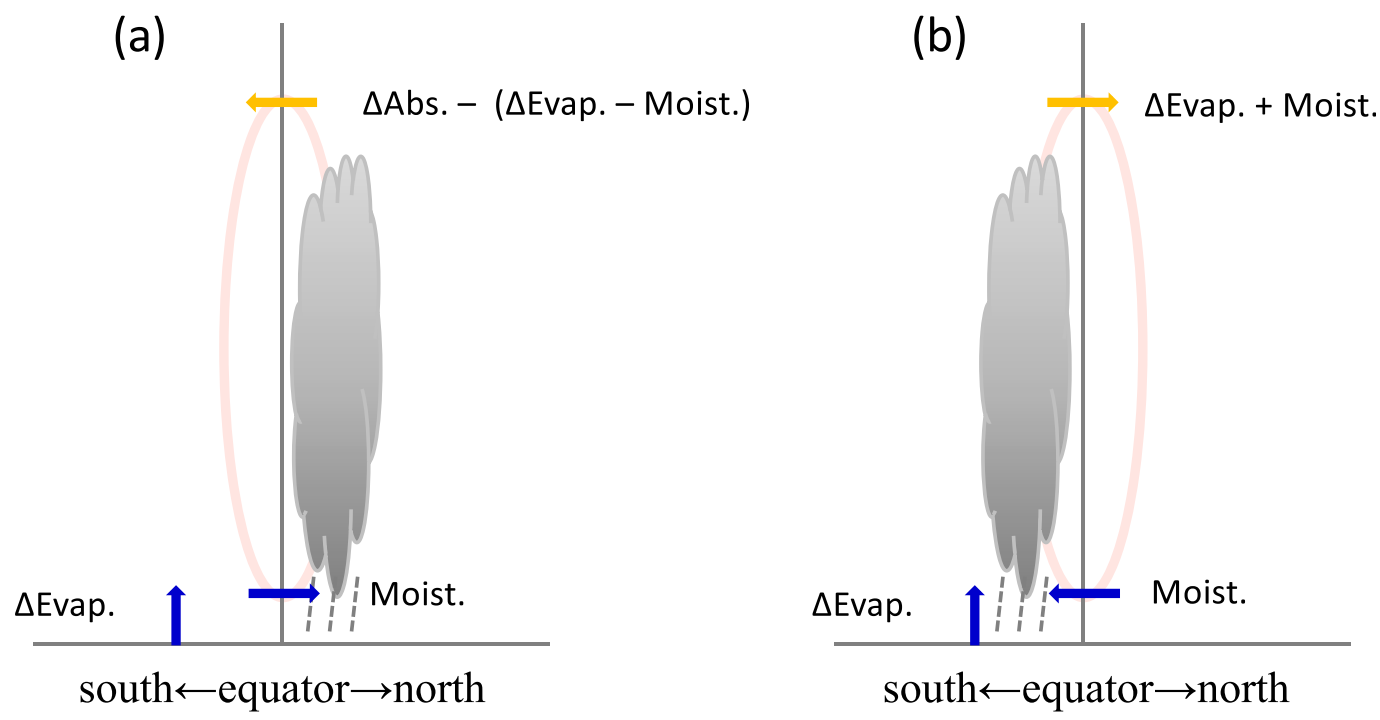

FIG. 8. Schematic representations of the mechanisms by which (a) $\mathrm{BC}$ and (b) $\mathrm{SO}_{4}$ impact the position of the ITCZ. Blue arrows: moisture transport, including evaporation (Evap.) and cross-equatorial moisture transport (Moist.); orange arrows: dry energy transport; evaporation and moisture next to orange arrows stand for the energy transport equivalent to them; Abs. represents the instantaneous absorption caused by $\mathrm{BC}$ in the atmosphere; $\Delta$ means interhemispheric contrast; pink circles show the anomalous circulations caused by $\mathrm{BC}_{\text {and }} \mathrm{SO}_{4}$ with the anomalous cross-equatorial energy and moisture transports as their upper and lower branches.

precipitation response. The difference between $\mathrm{BC}$ and $\mathrm{SO}_{4}$ in terms of the proportion of the precipitation response is attributable to the different ways in which the two types of aerosols change the atmospheric radiation budget. For BC, instantaneous atmospheric absorption dominates the total change in the atmospheric radiation budget. However, for $\mathrm{SO}_{4}$, the noncloud responsemainly associated with column water vapor changedominates the total change in the atmospheric radiation budget.

By changing the atmospheric cross-equatorial heat transport, $\mathrm{BC}$ and $\mathrm{SO}_{4}$ cause northward and southward shifts of the ITCZ, respectively. The ITCZ displacements and the atmospheric cross-equatorial heat transport changes caused by the two types of aerosols have a good linear relationship, with a regression coefficient of about $-3^{\circ} \mathrm{PW}^{-1}$. The $\mathrm{BC}$-induced northward shift of the ITCZ takes place mainly through the fast precipitation response, as the basic driving force for the $\mathrm{BC}$ induced southward atmospheric cross-equatorial heat transport anomaly is the interhemispheric contrast in the instantaneous atmospheric absorption caused by BC. In contrast, the $\mathrm{SO}_{4}$-induced southward shift of the ITCZ takes place through the slow precipitation response, and the largest contributor to the $\mathrm{SO}_{4}$-induced northward atmospheric cross-equatorial heat transport anomaly is the evaporation response (i.e., evaporation is suppressed more greatly in the $\mathrm{NH}$ than in the $\mathrm{SH}$ ).
By comparing the precipitation responses caused by $\mathrm{BC}$ and $\mathrm{SO}_{4}$ simulated in the CGCM and $\mathrm{SOM}$, it is found that the SOM exaggerates both the global mean precipitation response and the ITCZ shift, and the latter is exaggerated much more obviously than the former. The SOM exaggerates the ITCZ shifts caused by BC and $\mathrm{SO}_{4}$ by suppressing the role of the ocean in the meridional heat transport response. This underscores the importance of employing a fully coupled ocean model when studying the tropical climate response to aerosol forcing.

In general, this work demonstrates that the different precipitation responses caused by $\mathrm{BC}$ and $\mathrm{SO}_{4}$, both on global and tropical scales, are determined by their different ways in changing the atmospheric energy budget and its hemispheric asymmetry. However, uncertainties still exist and future work is needed. For example, we obtained a large negative rapid adjustment (about $-0.7 \mathrm{RF}$ ) for BC in section $3 \mathrm{a}$, but previous studies have also suggested various magnitudes of rapid adjustment for BC, including those much smaller than in this study (Bond et al. 2013). On the other hand, clouds were shown to play a primary role in determining the rapid adjustment of BC in this study; plus, Kang et al. (2009) and Voigt et al. (2014) suggested that changes to the treatment of clouds could exert a considerable impact on the atmospheric energy transport over the tropics, and thereby on the ITCZ shift, implying that it is 
important to study the precipitation responses caused by aerosols with different cloud schemes.

Acknowledgments. This study was supported by the Environment Research and Technology Development Fund (S-12) of the Environmental Restoration and Conservation Agency and by the Integrated Research Program for Advancing Climate Models (TOUGOU program) from the Ministry of Education, Culture, Sports, Science and Technology (MEXT), Japan; and by the JAXA/EarthCARE project.

\section{REFERENCES}

Allen, R. J., 2015: A 21st century northward tropical precipitation shift caused by future anthropogenic aerosol reductions. J. Geophys. Res., 120, 9087-9102, https://doi.org/10.1002/ 2015JD023623.

—, A. T. Evan, and B. B. B. Booth, 2015: Interhemispheric aerosol radiative forcing and tropical precipitation shifts during the late twentieth century. J. Climate, 28, 8219-8246, https://doi.org/10.1175/JCLI-D-15-0148.1.

Bala, G., K. Caldeira, and R. Nemani, 2010: Fast versus slow response in climate change: Implications for the global hydrological cycle. Climate Dyn., 35, 423-434, https://doi.org/10.1007/ s00382-009-0583-y.

Boer, G. J., 1993: Climate change and the regulation of the surface moisture and energy budgets. Climate Dyn., 8, 225-239, https://doi.org/10.1007/BF00198617.

Bond, T. C., and Coauthors, 2013: Bounding the role of black carbon in the climate system: A scientific assessment. J. Geophys. Res. Atmos., 118, 5380-5552, https://doi.org/10.1002/jgrd.50171.

Boucher, O., and Coauthors, 2013: Clouds and aerosols. Climate Change 2013: The Physical Science Basis, T. F. Stocker et al., Eds., Cambridge University Press, 571-657.

Broccoli, A. J., K. A. Dahl, and R. J. Stouffer, 2006: Response of the ITCZ to Northern Hemisphere cooling. Geophys. Res. Lett., 33, L01702, https://doi.org/10.1029/2005GL024546.

Chiang, J. C. H., and C. M. Bitz, 2005: Influence of high latitude ice cover on the marine intertropical convergence zone. Climate Dyn., 25, 477-496, https://doi.org/10.1007/s00382-005-0040-5.

Chung, S. H., and J. H. Seinfeld, 2005: Climate response of direct radiative forcing of anthropogenic black carbon. J. Geophys. Res., 110, D11102, https://doi.org/10.1029/2004JD005441.

Clark, S. K., Y. Ming, I. M. Held, and P. J. Phillipps, 2018: The role of the water vapor feedback in the ITCZ response to hemispherically asymmetric forcings. J. Climate, 31, 3659-3678, https://doi.org/10.1175/JCLI-D-17-0723.1.

Donohoe, A., J. Marshall, D. Ferreira, and D. Mcgee, 2013: The relationship between ITCZ location and cross-equatorial atmospheric heat transport: From the seasonal cycle to the last glacial maximum. J. Climate, 26, 3597-3618, https://doi.org/ 10.1175/JCLI-D-12-00467.1.

Frierson, D. M. W., and Coauthors, 2013: Contribution of ocean overturning circulation to tropical rainfall peak in the Northern Hemisphere. Nat. Geosci., 6, 940-944, https://doi.org/ 10.1038/ngeo1987.

Green, B., and J. Marshall, 2017: Coupling of trade winds with ocean circulation damps ITCZ shifts. J. Climate, 30, 43954411, https://doi.org/10.1175/JCLI-D-16-0818.1.
Hansen, J., and Coauthors, 2002: Climate forcings in Goddard Institute for Space Studies SI2000 simulations. J. Geophys. Res., 107, 4347, https://doi.org/10.1029/2001JD001143.

Hasumi, H., 2015: CCSR Ocean Component Model (COCO), version 4.0. Center for Climate System Research Rep. 25, 103 pp., https://ccsr.aori.u-tokyo.ac.jp/ hasumi/COCO/coco4. pdf.

Hawcroft, M., J. M. Haywood, M. Collins, A. Jones, A. C. Jones, and G. Stephens, 2017: Southern Ocean albedo, interhemispheric energy transports and the double ITCZ: Global impacts of biases in a coupled model. Climate Dyn., 48, 22792295, https://doi.org/10.1007/s00382-016-3205-5.

Haywood, J. M., and Coauthors, 2016: The impact of equilibrating hemispheric albedos on tropical performance in the HadGEM2-ES coupled climate model. Geophys. Res. Lett., 43, 395-403, https://doi.org/10.1002/2015GL066903.

Hwang, Y.-T., D. M. Frierson, and S. M. Kang, 2013: Anthropogenic sulfate aerosol and the southward shift of tropical precipitation in the late 20th century. Geophys. Res. Lett., 40, 2845-2850, https://doi.org/10.1002/grl.50502.

Kang, S. M., I. M. Held, D. M. W. Frierson, and M. Zhao, 2008: The response of the ITCZ to extratropical thermal forcing: Idealized slab-ocean experiments with a GCM. J. Climate, 21, 35213532, https://doi.org/10.1175/2007JCLI2146.1.

, D. M. W. Frierson, and I. M. Held, 2009: The tropical response to extratropical thermal forcing in an idealized GCM: The importance of radiative feedbacks and convective parameterization. J. Atmos. Sci., 66, 2812-2827, https://doi.org/ 10.1175/2009JAS2924.1.

, R. Seager, D. M. W. Frierson, and X. Liu, 2015: Croll revisited: Why is the Northern Hemisphere warmer than the Southern Hemisphere? Climate Dyn., 44, 1457-1472, https:// doi.org/10.1007/s00382-014-2147-z.

Kay, J. E., C. Wall, V. Yettella, B. Medeiros, C. Hannay, P. Caldwell, and C. Bitz, 2016: Global climate impacts of fixing the Southern Ocean shortwave radiation bias in the Community Earth System Model (CESM). J. Climate, 29, 4617-4636, https://doi.org/10.1175/JCLI-D-15-0358.1.

Kim, D., C. Wang, A. M. L. Ekman, M. C. Barth, and D. Lee, 2014: The responses of cloudiness to the direct radiative effect of sulfate and carbonaceous aerosols. J. Geophys. Res. Atmos., 119, 1172-1185, https://doi.org/10.1002/2013JD020529.

Kim, H., S. M. Kang, Y.-T. Hwang, and Y.-M. Yang, 2015: Sensitivity of the climate response to the altitude of black carbon in the northern subtropics in an aquaplanet GCM. J. Climate, 28, 6351-6359, https://doi.org/10.1175/JCLI-D15-0037.1.

Lin, L., A. Gettelman, Y. Xu, and Q. Fu, 2016: Simulated responses of terrestrial aridity to black carbon and sulfate aerosols. J. Geophys. Res., 121, 785-794, https://doi.org/10.1002/ 2015JD024100.

Mahajan, S., K. J. Evans, J. J. Hack, and J. E. Truesdale, 2013: Linearity of climate response to increases in black carbon aerosols. J. Climate, 26, 8223-8237, https://doi.org/10.1175/ JCLI-D-12-00715.1.

Marshall, J., A. Donohoe, D. Ferreira, and D. McGee, 2014: The ocean's role in setting the mean position of the Inter-Tropical Convergence Zone. Climate Dyn., 42, 1967-1979, https:// doi.org/10.1007/s00382-013-1767-z.

Ming, Y., V. Ramaswamy, and G. Persad, 2010: Two opposing effects of absorbing aerosols on global-mean precipitation. Geophys. Res. Lett., 37, L13701, https://doi.org/10.1029/ 2010GL042895. 
Myhre, G., and Coauthors, 2017: PDRMIP: A precipitation driver and response model intercomparison project-Protocol and preliminary results. Bull. Amer. Meteor. Soc., 98, 1185-1198, https://doi.org/10.1175/BAMS-D-16-0019.1.

Ocko, I. B., V. Ramaswamy, and Y. Ming, 2014: Contrasting climate responses to the scattering and absorbing features of anthropogenic aerosol forcings. J. Climate, 27, 5329-5345, https://doi.org/10.1175/JCLI-D-13-00401.1.

Pall, P., M. R. Allen, and D. A. Stone, 2007: Testing the ClausiusClapeyron constraint on changes in extreme precipitation under $\mathrm{CO}_{2}$ warming. Climate Dyn., 28, 351-363, https:// doi.org/10.1007/s00382-006-0180-2.

Samset, B. H., and Coauthors, 2016: Fast and slow precipitation responses to individual climate forcers: A PDRMIP multimodel study. Geophys. Res. Lett., 43, 2782-2791, https:// doi.org/10.1002/2016GL068064.

-, and Coauthors, 2018: Weak hydrological sensitivity to temperature change over land, independent of climate forcing. $n p j$ Climate Atmos. Sci., 1, 20173, https://doi.org/10.1038/s41612017-0005-5.

Schneider, T., T. Bischoff, and G. H. Haug, 2014: Migrations and dynamics of the intertropical convergence zone. Nature, $\mathbf{5 1 3}$, 45-53, https://doi.org/10.1038/nature13636.

Sherwood, S. C., and N. Nishant, 2015: Atmospheric changes through 2012 as shown by iteratively homogenized radiosonde temperature and wind data (IUKv2). Environ. Res. Lett., 10, 054007, https://doi.org/10.1088/1748-9326/10/5/054007.

Smith, C. J., and Coauthors, 2018: Understanding rapid adjustments to diverse forcing agents. Geophys. Res. Lett., 45, 12 023-12 031, https://doi.org/10.1029/2018GL079826.

Stephens, G. L., and T. D. Ellis, 2008: Controls of global-mean precipitation increases in global warming GCM experiments. $J$. Climate, 21, 6141-6155, https://doi.org/10.1175/2008JCLI2144.1.

— , M. Z. Hakuba, M. Hawcroft, J. M. Haywood, A. Behrangi, J. E. Kay, and P. J. Webster, 2016: The curious nature of the hemispheric symmetry of the earth's water and energy balances. Curr. Climate Change Rep., 2, 135-147, https://doi.org/ 10.1007/s40641-016-0043-9.

Stjern, C. W., and Coauthors, 2017: Rapid adjustments cause weak surface temperature response to increased black carbon concentrations. J. Geophys. Res., 122, 11462-11481, https:// doi.org/10.1002/2017JD027326.

Suzuki, K., and T. Takemura, 2019: Perturbations to global energy budget due to absorbing and scattering aerosols. J. Geophys. Res., 124, 2194-2209, https://doi.org/10.1029/2018JD029808.
_ , G. L. Stephens, and J.-C. Golaz, 2017: Significance of aerosol radiative effect in energy balance control on global precipitation change. Atmos. Sci. Lett., 18, 389-395, https:// doi.org/10.1002/asl.780.

Takemura, T., and K. Suzuki, 2019: Weak global warming mitigation by reducing black carbon emissions. Sci. Rep., 9, 4419, https://doi.org/10.1038/s41598-019-41181-6.

__ , T. Nozawa, S. Emori, T. Y. Nakajima, and T. Nakajima, 2005: Simulation of climate response to aerosol direct and indirect effects with aerosol transport-radiation model. J. Geophys. Res., 110, D02202, https://doi.org/10.1029/ 2004JD005029.

_- M. Egashira, K. Matsuzawa, H. Ichijo, T. O'ishi, and A. AbeOuchi, 2009: A simulation of the global distribution and radiative forcing of soil dust aerosols at the Last Glacial Maximum. Atmos. Chem. Phys., 9, 3061-3073, https://doi.org/ 10.5194/acp-9-3061-2009.

Twomey, S., 1977: The influence of pollution on the shortwave albedo of clouds. J. Atmos. Sci., 34, 1149-1152, https://doi.org/ 10.1175/1520-0469(1977)034<1149:TIOPOT>2.0.CO;2.

Voigt, A., S. Bony, J.-L. Dufresne, and B. Stevens, 2014: The radiative impact of clouds on the shift of the Intertropical Convergence Zone. Geophys. Res. Lett., 41, 4308-4315, https://doi.org/10.1002/2014GL060354.

_ , and Coauthors, 2017: Fast and slow shifts of the zonal-mean intertropical convergence zone in response to an idealized anthropogenic aerosol. J. Adv. Model. Earth Syst., 9, 870-892, https://doi.org/10.1002/2016MS000902.

Wang, Z., L. Lin, M. Yang, Y. Xu, and J. Li, 2017: Disentangling fast and slow responses of the East Asian summer monsoon to reflecting and absorbing aerosol forcings. Atmos. Chem. Phys., 17, 11 075-11 088, https://doi.org/10.5194/acp-1711075-2017.

Watanabe, M., and Coauthors, 2010: Improved climate simulation by MIROC5: Mean states, variability, and climate sensitivity. J. Climate, 23, 6312-6335, https://doi.org/10.1175/ 2010JCLI3679.1.

Yoshimori, M., and A. J. Broccoli, 2008: Equilibrium response of an atmosphere-mixed layer ocean model to different radiative forcing agents: Global and zonal mean response. J. Climate, 21, 4399-4423, https://doi.org/10.1175/2008JCLI2172.1.

, A. A.-Ouchi, and A. Laîné, 2017: The role of atmospheric heat transport and regional feedbacks in the Arctic warming at equilibrium. Climate Dyn., 49, 3457-3472, https://doi.org/ 10.1007/s00382-017-3523-2. 